\title{
Assessing Legislative Interest for a Sugar-Sweetened Beverage Tax in a Midwestern State
}

Stephanie Murray, M.D. ${ }^{1}$, Colleen Loo-Gross, M.D., M.P.H. ${ }^{1}$, Mary Pham, M.D. ${ }^{1}$, Sonja Armbruster, M.A.C. ${ }^{2}$, Kelly Konda, B.A. ${ }^{1}$, Elizabeth Ablah, Ph.D., M.P.H. ${ }^{1}$

${ }^{1}$ University of Kansas School of Medicine-Wichita

Department of Preventive Medicine and Public Health

${ }^{2}$ Sedgwick County Health Department

Division of Health Protection and Promotion, Wichita, KS

\begin{abstract}
Background. This study sought to ascertain the opinions of members of the Kansas Legislature regarding pending sugar-sweetened beverage taxation legislation, including perceptions that such a tax would generate revenue or be associated with personal sugar-sweetened beverage consumption habits.
\end{abstract}

Methods. This study utilized a cross-sectional survey design and was conducted by administering an electronic or telephone survey of the 2010-2011 Kansas Legislature. Publiclylisted contact information for the 165 members in both chambers of the 2010-2011 Kansas Legislature was obtained. State legislators were invited via e-mail, telephone, or both to complete the survey. The main outcome measure was the degree of agreement or disagreement with the idea of sugar-sweetened beverage taxation.

Results. Seventy-eight legislators (47.3\%) responded. Of these, 90.5\% disagreed or strongly disagreed with taxation of sugar-sweetened beverages, and $86.5 \%$ disagreed or strongly disagreed with taxation of sugar-sweetened beverages if generated funds were set aside to subsidize healthy choices. Party affiliation, geographic area represented, and personal consumption of sugar-sweetened behaviors were not associated significantly with legislators' opinions of sugar-sweetened beverage taxation.

Conclusions. The majority of respondents in the Kansas Legislature reported opposing a sugarsweetened beverage tax. While some respondents identified obesity as a problem, taxation of sugar-sweetened beverages was not a favorable option among Kansas legislators.

KS J Med 2015; 8(1):1-7.

\section{Introduction}

Consumption of sugar-sweetened beverages (SSBs, beverages with any added caloric sweetener) is associated with increased caloric intake, weight gain, and obesity, ${ }^{1,2}$ which translates into strains upon health status and increased medical expenditures. $^{3}$ SSB consumption is associated with dental caries, poor oral health, type 2 diabetes, heart disease, gout, and sleeplessness. ${ }^{2,4-7}$ SSBs contribute little toward health and high levels of consumption in the population are correlated with the rising incidence of obesity. ${ }^{1-2,8}$
Considering this correlation to obesity and health risks (of which the medical costs for treatment represent 9.1\% of United States annual health care expenditures) ${ }^{9}$, in a climate of state budget shortfalls, taxation on SSBs present a potential vehicle for intervention. The public health strategy is based upon prior success of tobacco taxes contributing $\$ 9.3$ billion annually to fund tobacco cessation efforts nationwide. ${ }^{10}$

Direct benefits to reducing obesity from a national tax of 1 cent per 20 ounces could be as much as 3.8 pounds lost per year per 
adult and 4.5 pounds lost per year per child due to the reduction of caloric intake from SSB. ${ }^{11}$ Direct economic gain are dependent upon the level of taxation, ${ }^{12}$ but the most notable estimation in annual revenue would be $\$ 14.9$ billion for a national tax of 1 cent

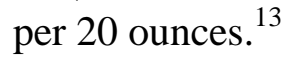

An SSB tax has the potential to generate funds for governments to enact obesity prevention initiatives. SSBs are part of taxes upon multiple categories of food and drink in 35 states. ${ }^{14}$ Yet, these taxes have not shown meaningful effects upon SSB consumption and/or obesity. ${ }^{15-18}$ However, the existing rates in the 35 states that tax SSBs (mean tax rate of $5.2 \%$ ) are not earmarked for programs related to health.

The level of support for the concept of a SSB tax can increase if explained in such a manner that generated funds would be devoted to health improvement efforts. For instance, a 2008 poll of New York State residents suggested that $52 \%$ of respondents supported a soda tax; $;^{12} 72 \%$ supported such a tax if the revenue would be used to support initiatives for the prevention of obesity in children and adults. ${ }^{19}$

Similar increases in approval, when the question is framed in such a manner as to highlight the intended usage of the funds, have been indicated in polls of New York State residents conducted by the Citizens' Committee for Children of New York $(2008)^{20}$ and the Henry J. Kaiser Family Foundation (2009). ${ }^{21}$ This assertion has yet to be tested in the literature. However, more recent polling data suggested public opinion is divided on the issue, as over $50 \%$ of adults surveyed oppose taxes of sugary products like candy and soft drinks and just over a quarter of respondents (26\%) indicated they think such taxes could reduce obesity. $^{22}$ Additionally, opinions and policies on SSB taxes not only vary from locale to locale, but based on the type, amount, and scope of the proposed taxation. $^{14}$

The current study assessed the opinions of Kansas legislators regarding taxation of SSBs in Kansas. This study aimed to elicit opinions regarding the use of potential tax revenue and determine if support for a tax would be associated with the intended usage of the potential tax revenue. Additionally, this project assessed the SSB consumption habits of Kansas legislators, both in frequency and quantity, and whether these personal beverage choices are associated with individual opinions regarding the proposed taxation. No previous studies involving the Kansas Legislature had been conducted to assess the issue of increased caloric intake through SSBs.

\section{Methods}

For the purpose of this study, researchers defined sugar-sweetened beverages as carbonated or noncarbonated drinks that are sweetened with added caloric sugars (sucrose or high-fructose corn syrup), including non-diet soft drinks, fruit drinks, lemonade, fruit punch, energy drinks, and other sweetened beverages. Sugared beverages were defined as carbonated or noncarbonated drinks that are sweetened with artificial (non-caloric) sweeteners and excluded from the study. ${ }^{23}$

Participants. Kansas was selected as the state for analysis owing to geographic proximity to the researchers and the state's status as being one of 17 to fail to pass SSB tax legislation between 2009 and 2010 . Senate Bill 567 was introduced into the Kansas Senate in 2010 as an excise tax on retailers and manufacturers, but failed to pass the Senate Assessment and Taxation Committee. The bill was introduced for the purpose of generating revenue to address the state's budget shortfall, as no monies were earmarked for obesity prevention and 
benefits to health were secondary. The study population was the 165 members of the 2010-2011 Kansas Legislature, including the full membership of the Senate and House of Representatives.

Instrument. A 17-item, electronic survey was developed for this study. The survey included demographic items (e.g., urban vs rural constituency, political party, gender) and Likert scale items assessing support of a SSB tax as well as support contingent upon generated funds being devoted to subsidization of health initiatives. There were 15 close-ended items, one item to itemize the number of servings of various types of beverages they had consumed in the past week, and an open-ended item at the conclusion of the instrument. Two of the close-ended questions were Likert scale questions and 13 were categorical items (e.g., food recall quantities, political parties, community size). All other than the Likert scale items were used to classify respondents. The survey instrument was designed for this project and its psychometric properties were not measured.

The instrument included individual dietary recall items assessing beverage consumption according to frequency and typical service size. The intent of the dietary recall was to compare sugar-tax perceptions and beverage-intake patterns. The dietary recall was modeled after surveys implemented in similar studies. ${ }^{24-26}$ The survey instrument presented legislators with five mutually exclusive beverage categories and asked them to indicate how often they consumed the each beverage in the past month, either per day, per week, or per month. The beverage categories, derived from NHANES III and NHANES 19942004 ${ }^{26-27}$ were: 1) milk (including milk consumed with cereal), 2) non-diet sugared soda or pop, 3) $100 \%$ pure fruit juice, 4) sweetened coffee or tea, and 5) sweetened fruit, sports, or energy drinks.
Procedures. Upon obtaining Institutional Review Board approval, researchers electronically invited all 165 current members of the 2010-2011 Kansas Senate and House of Representatives to complete the assessment. Contact information for the Kansas legislators was obtained from publicly-accessible websites, individual campaign sites, and the publicly-accessible legislative directory on the Kansas Secretary of State website. Invitations were sent via an introductory e-mail from the electronic survey host, SurveyMonkey ${ }_{\circledast}$, with each email containing an embedded link to the assessment. The invitations explained the purpose of the survey and included an explanation of the voluntary nature of study participation. An eight-week window in which to complete the survey was noted in the initial e-mail, with reminder e-mails sent out to non-responders after the first and second weeks. To ensure maximal response, all 165 potential respondents were contacted directly at their publicly-listed phone numbers at the conclusion of two weeks of electronic data collection and offered the option of completing the survey via telephone. Legislators with unlisted e-mail addresses were contacted by phone only. Data were collected from November 1, 2010 through January 1, 2011.

Statistical analysis. Upon conclusion of the data collection period, results were compiled via direct download from SurveyMonkey ${ }_{\circledast}$ and entered from telephone data into spreadsheet format. Data and descriptive statistics were calculated to define and categorize responses. Results were reported by frequency and percentage.

\section{Results}

Seventy-eight (78) of the 165 Kansas senators and representatives participated in the survey, resulting in a $47.3 \%$ response rate. Among the respondents, $82.4 \%(n=61)$ identified themselves as Republican, $17.6 \%$ 
( $\mathrm{n}=13$ ) identified themselves as Democrat, and $5.1 \%(n=4)$ of participants declined to comment on their political party. Among the respondents, $57.5 \%$ identified themselves as representing urban areas, 37.1\% identified themselves as representing rural areas, and $5.1 \%$ declined to comment on the type of area they predominantly represented.

The majority of participants (90.5\%) strongly disagreed or disagreed with the imposition of taxes on SSBs in Kansas. Further, $86.5 \%$ strongly disagreed or disagreed with being in favor of taxes on SSBs in Kansas, even when generated funds were to be set aside to subsidize "healthy choices" (e.g., public health education/ promotion, obesity prevention programs, or provision of healthy foods).

Of the $13.5 \%$ of respondents who were in favor of a sales tax that would be used to subsidize healthy choices, $50 \%$ reported that the portion of funds ideally set aside to subsidize healthy choices should be between $51 \%$ and $75 \%$; the other 50\% suggested setting aside $76 \%$ to $100 \%$ of the funds.

Political party affiliation. Most Republicans (91.5\%) and Democrats (84.6\%) strongly disagreed or disagreed with taxes on SSBs. Also, 88.1\% of Republicans and $76.9 \%$ of Democrats reported that they strongly disagreed or disagreed with taxes on sugar-sweetened beverages, even when generated funds were to be set aside to subsidize healthy choices.

Geographic area represented. Of the $57.7 \%$ of respondents representing urban areas, $93.0 \%$ strongly disagreed or disagreed with a tax on SSBs. Among respondents representing rural areas, $86.2 \%$ strongly disagreed or disagreed with the tax. Still, $89.7 \%$ and $83.7 \%$ of respondents who represented rural and urban areas, respectively, reported that they strongly disagreed or disagreed with the taxation of SSBs, even when generated funds would be set aside to subsidize healthy choices.
Personal consumption. Participants were asked if they had consumed milk, non-diet sugared soda or pop, $100 \%$ fruit juice, sweetened coffee or tea, and sweetened fruit sports or energy drinks within the last 30 days. Based on their responses, $80.3 \%$ consumed at least one serving of milk, $71.8 \%$ consumed $100 \%$ fruit juice, $41.9 \%$ consumed non-diet sugared soda or pop, 23.0\% consumed sweetened fruit sports or energy drinks, and $20.3 \%$ consumed sweetened coffee or tea within the last 30 days (Table 1). However, participants' reported consumption of beverages was not associated significantly with their position on the taxation of sugar-sweetened beverages.

Table 1. Percent of respondents who reported beverage consumption in the last 30 days.

\begin{tabular}{|l|c|c|}
\hline & None & $\begin{array}{c}\text { At Least } \\
\text { One } \\
\text { Beverage }\end{array}$ \\
\hline Milk & $19.7 \%$ & $80.3 \%$ \\
\hline $100 \%$ Fruit Juice & $28.2 \%$ & $71.8 \%$ \\
\hline $\begin{array}{l}\text { Non-Diet Sugared Soda } \\
\text { or Pop }\end{array}$ & $58.1 \%$ & $41.9 \%$ \\
\hline $\begin{array}{l}\text { Sweetened Fruit, Sports, } \\
\text { or Energy Drinks }\end{array}$ & $77.0 \%$ & $23.0 \%$ \\
\hline $\begin{array}{l}\text { Sweetened Coffee or } \\
\text { Tea }\end{array}$ & $79.7 \%$ & $20.3 \%$ \\
\hline
\end{tabular}

\section{Discussion}

The majority of Kansas legislator respondents were not in favor of a sugarsweetened beverage tax in the state. No major differences existed in opinions among legislators regarding political party affiliation or geographical area of representation. Furthermore, their own sugar-sweetened beverage consumption did not appear to be associated with opinions regarding a sugar-sweetened beverage tax.

Prior to this study, no research had assessed opinions of Kansas legislators on 
an SSB tax. Additionally, no similar studies had been conducted addressing this topic in other state legislatures. Other studies focusing on SSB taxes had focused on the nature of the policies or their potential for revenue generation rather than the opinions and health behaviors of the legislators who actually vote on these policies. ${ }^{12,14}$ As members of government representing their constituents at the state level, the views of policy-makers are important when considering public health policy interventions. An SSB tax could be used to update built environments, foster the growth and consumption of local vegetables and fruits, support community gardens, and/or subsidize the costs of vegetables and fruits.

Limitations. Non-response bias may have occurred in this study. The possibility exists that legislators who chose to participate in this study had stronger opinions on the topic, such as increased opposition to a rise in taxes. Additionally, these results are less generalizable beyond Kansas legislators, though they may be applicable in other Republican-dominated states. However, the purpose of this study was to assess opinions specifically within the Kansas legislature. Thus, the $47.3 \%$ response rate serves as an appropriate sample for this population.

Although the original bill was an excise tax on retailers and manufacturers, the survey

\section{References}

${ }^{1}$ Malik VS, Schulze MB, Hu FB. Intake of sugar-sweetened beverages and weight gain: A systematic review. Am J Clin Nutr 2006; 84(2):274-288. PMID: 16895873.

2 Vartanian LR, Schwartz MB, Brownell KD. Effects of soft drink consumption on nutrition and health: A systematic review and meta-analysis. Am J Public Health 2007; 97(4):667-675. PMID: 17329656.

${ }^{3}$ National Center for Health Statistics. Public Health Service. Health: United assessed taxation without specifying if this would be a sales or excise tax or referring directly to statutory language of Kansas Senate Bill 567. Consumers typically are unaware of sales taxes, registered at the time of payment and added onto the sale price, whereas an excise tax would affect the overall shelf price thus immediately signaling to the consumer the higher price and increasing the likelihood of impacting purchasing patterns. ${ }^{14}$ By failing to define what was meant by tax, it was left to the respondent to deduce whether the survey was inquiring about a sales tax or an excise tax, a distinction which previous research has indicated is of critical importance. ${ }^{14}$

\section{Conclusions}

This study suggested that the 2010-2011 Kansas Legislature would not support implementation of a tax on SSBs. Legislators provided reasons for not supporting the tax, including not supporting any increase in taxes, uncertainty that taxation would be successful in decreasing caloric intake, volitions against interfering with individual freedoms, and a desire to support the use of corn syrup in this highly agricultural state. Additional strategies to decrease the accessibility of SSBs are necessary for the development and implementation of effective public health and economic interventions.

States 2008 with Special Features on Young Adults. 2008. Available at: http://www.cdc.gov/nchs/data/hus/hus08.p df. Accessed 5 August, 2014.

${ }^{4}$ Heller KE, Burt BA, Eklund SA. Sugared soda consumption and dental caries in the United States. J Dent Res 2001; 80(10):1949-1953. PMID: 11706958.

${ }^{5}$ Calamaro CJ, Mason TB, Ratcliffe SJ. Adolescents living the 24/7 lifestyle: Effects of caffeine and technology on sleep 
duration and daytime functioning. Pediatrics 2009; 123(6):e1005-e1010. PMID: 19482732.

${ }^{6}$ Choi HK, Willett W, Curhan G. Fructoserich beverages and risk of gout in women. JAMA 2010; 304(20):2270-2278. PMID: 21068145.

${ }^{7}$ Malik VS, Popkin BM, Bray GA, Després JP, Hu FB. Sugar-sweetened beverages, obesity, type 2 diabetes mellitus, and cardiovascular disease risk. Circulation 2010; 121(11):1356-1364. PMID: 20308626.

${ }^{8}$ Pereira MA. The possible role of sugarsweetened beverages in obesity etiology: A review of the evidence. Int J Obes 2006; 30:S28-S36.

${ }^{9}$ Finkelstein EA, Trogdon JG, Cohen JW, Dietz W. Annual medical spending attributable to obesity: Payer- and servicespecific estimates. Health Aff 2009; 28(5):W822-W831. PMID: 19635784.

${ }^{10}$ US Department of Health and Human Services. Promoting healthy lifestyles: Policy, program, and personal recommendations for reducing cancer risk. President's Cancer Panel annual report. 2007. Available at: http://deainfo.nci.nih.gov/ advisory/pcp/annualReports/pcp07rpt/pcp07r pt.pdf.

${ }^{11}$ Smith TA, Biing-Hwan L, Jong-Ying L. Taxing caloric sweetened beverages: Potential effects on beverage consumption, caloric intake, and obesity, US Department of Agriculture, Economic Research Service. 2010. Available at: http://core.ac. uk/download/pdf/6459809.pdf

${ }^{12}$ Andreyeva T, Chaloupka FJ, Brownell $\mathrm{KD}$. Estimating the potential of taxes on sugar-sweetened beverages to reduce consumption and generate revenue. Prev Med 2011; 52(6):413-416. PMID: 21443899.

${ }^{13}$ Brownell KD, Farley T, Willett C, et al. The public health and economic benefits of taxing sugar-sweetened beverages. N Engl
J Med 2009; 361(16):1599-1605. PMID: 19759377.

${ }^{14}$ Chriqui JF, Chaloupka FJ, Powell LM, Eidson SS. A typology of beverage taxation: Multiple approaches for obesity prevention and obesity prevention-related revenue generation. J Public Health Policy 2013; 34(3):403-423. PMID: 23698157.

${ }^{15}$ Finkelstein EA, Zhen C, Nonnemaker J, Todd JE. Impact of targeted beverage taxes on higher- and lower-income households. Arch Intern Med 2010; 170(22):20282034. PMID: 21149762.

${ }^{16}$ Kim D, Kawachi I. Food taxation and pricing strategies to "thin out" the obesity epidemic. Am J Prev Med 2006; 30(5): 430-437. PMID: 16627131.

${ }^{17}$ Powell LM, Chriqui J, Chaloupka FJ. Associations between state-level soda taxes and adolescent body mass index. $\mathrm{J}$ Adolesc Health 2009; 45(3 Suppl):S57S63. PMID: 19699437.

${ }^{18}$ Sturm R, Powell LM, Chriqui JF, Chaloupka FJ. Soda taxes, soft drink consumption, and children's body mass index. Health Aff 2010; 29(5):1052-1058. PMID: 20360173.

${ }^{19}$ Brownell KD. The chronicling of obesity: Growing awareness of its social, economic, and political contexts. J Health Polit Policy Law 2005; 30(5):955-964. PMID: 16477793.

${ }^{20}$ Citizens' Committee for Children of New York, Inc. Voter Preferences for Closing the New York State Budget Gap. 2008. Available at: http://www.yaleruddcenter. org/resources/upload/docs/what/policy/SS Btaxes/NYPoll12.08.pdf.

${ }^{21}$ The Henry J. Kaiser Family Foundation. Kaiser Health Tracking Poll. February 2009. Available at: http://kaiserfamilyfo undation.files.wordpress.com/2013/01/786 6.pdf.

${ }^{22}$ Harris Interactive. Most Americans oppose sugar, candy taxes. 25 April, 2013. Available at: http://www.harrisinteractive. 
com/NewsRoom/PressReleases/tabid/446/ mid/1506/articleId/1185/ctl/ReadCustom \%20Default/Default.aspx.

${ }^{23}$ Popkin BM, Armstrong LE, Bray GM, Caballero B, Frei B, Willett WC. A new proposed guidance system for beverage consumption in the United States. Am J Clin Nutr 2006; 83(3):529-542. PMID: 16522898.

${ }^{24}$ Berkey CS, Rockett HR, Field AE, Gillman MW, Colditz GA. Sugar-added beverages and adolescent weight change. Obes Res 2004; 12(5):778-788. PMID: 15166298.

${ }^{25}$ Schulze MB, Manson JE, Ludwig DS, et al. Sugar-sweetened beverages, weight gain, and incidence of type 2 diabetes in young and middle-aged women. JAMA 2004; 292(8):927-934. PMID: 15328324.

${ }^{26}$ West DS, Bursac Z, Quimby D, et al. Self-reported sugar-sweetened beverage intake among college students. Obesity 2006; 14(10):1825-1831. PMID: 17062813.

${ }^{27}$ Bleich SN, Wang YC, Wang Y, Gortmaker SL. Increasing consumption of sugar-sweetened beverages among US adults: $1988-1994$ to $1999-2004$. Am J Clin Nutr 2009; 89(1):372-381. PMID: 19056548.

Keywords: public policy, beverages, sweetening agents, taxes, legislation 